\title{
Giant Median Lobe Hyperplasia of the Prostate Mimicking Bladder Tumor: A Case Report
}

\author{
Samet Şenel $^{1}$ (I) Cüneyt Özden ${ }^{1}$ (i) Binhan Kağan Aktaş ${ }^{1}$ (I) \\ Cevdet Serkan Gökkayaa ${ }^{1}$ (D) Şahin Paşalı ${ }^{1}$ (D)
}

1 Ankara City Hospital, Department of Urology, Ankara, Turkey.

\begin{abstract}
Benign prostatic hyperplasia is a common cause of bladder outlet obstruction and may cause macroscopic hematuria. Giant median lobe hyperplasia is very rare and its definition is not clear. In this case report, the diagnosis and treatment of a case with giant median lobe hyperplasia of the prostate mimicking a bladder tumor were evaluated. A 65-year-old male patient was admitted to our clinic with a 9-month history of intermittent hematuria. Abdominopelvic computed tomography revealed a mass measuring 95x85x57 mm filling the bladder. A distinct anatomical plane between the mass and the seminal vesicles could not be identified. In the urethrocystoscopy, it was determined that the mass was the giant median lobe of the prostate. Open suprapubic prostatectomy was performed. A total of $330 \mathrm{~g}$ prostate tissue consisting of $180 \mathrm{~g}$ median lobe was enucleated. Giant median lobe hyperplasia of the prostate is a rare pathology and may mimic a bladder tumor by causing painless hematuria.
\end{abstract}

Key words: Giant Prostatic Hyperplasia, Case Report, Suprapubic Open Prostatectomy.

\section{INTRODUCTION}

Benign prostate hyperplasia (BPH) is histologically defined as oblong hyperplastic tissue nodules, most often composed of epithelium and stroma. (1). The prostate gland due to $\mathrm{BPH}$ can sometimes be very large. Giant prostatic hyperplasia is a rare condition characterized by a BPH weighing more than $500 \mathrm{~g}$ (2). In most of the cases reported in the literature, the prostate is often overgrown by lateral lobes (3). In the literature, the giant median lobe hyperplasia of the prostate is very rare and its definition is not clear. In this case report, the diagnosis and treatment of a case with giant median lobe hyperplasia of the prostate mimicking a bladder tumor was evaluated. 


\section{CASE REPORT}

A 65-year-old male patient presented to our clinic with intermittent painless hematuria ongoing for 9 months in January 2018. He had no voiding symptoms. He had a history of transurethral resection of the prostate due to BPH in 2010 and 2015 and prostate biopsy due to high level of serum prostate-specific antigen (PSA) in 2016 (16 ng / dL) (pathology benign). Physical examination was normal. Digital examination revealed a large but benign and non-nodular prostate. Chest x-ray, hemogram and serum biochemistry were normal. Serum PSA level was 21 ng / ml. Abdominopelvic computed tomography showed a contrasting mass measured $95 \times 85 \times 57 \mathrm{~mm}$ occupying the whole bladder (Figure 1). A distinct anatomical plane between the mass and the seminal vesicles could not be identified. An urethrocystoscopy was performed and it was determined that the mass defined in the tomography was the giant median lobe of the prostate. The patient underwent open suprapubic prostatectomy surgery. A total of $330 \mathrm{~g}$ prostate tissue including $180 \mathrm{~g}$ median lobe was enucleated. The amount of peri-operative bleeding was approximately 350 cc. Postoperative biochemistry and hemogram values were normal. The patient was discharged on the postoperative 7 th day. Pathological examination of the surgical specimen was reported as nodular hyperplasia.

Figure-1: a) The mass completely filling the bladder b) Lateral lobes of the prostate

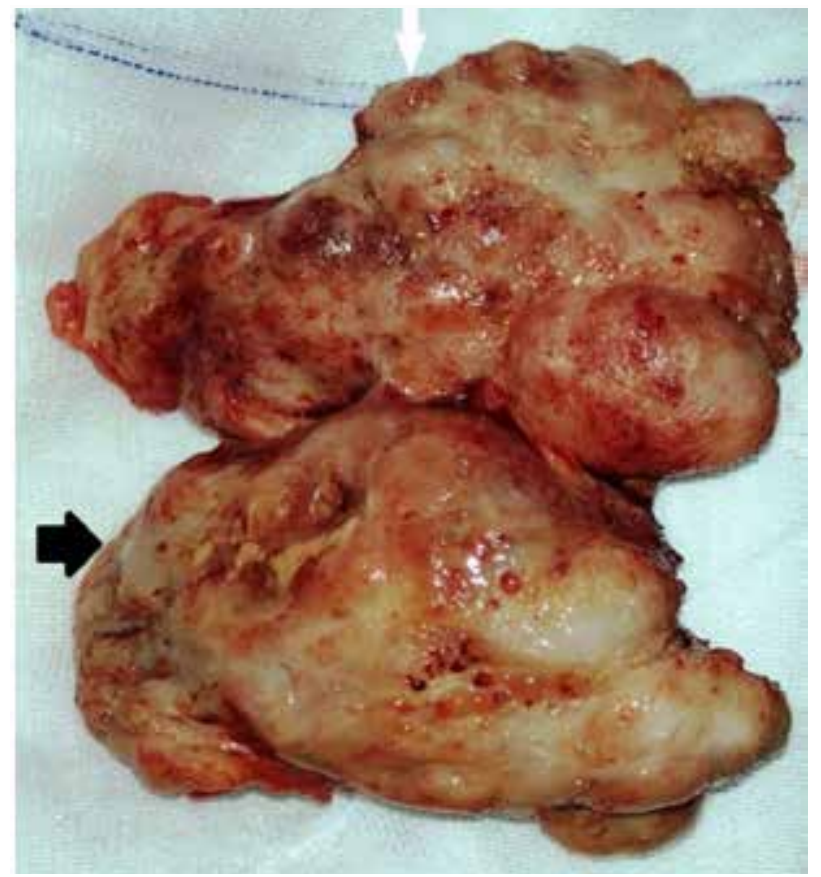

Figure-2: Prostate tissue consisting of enucleated median (marked with white arrow) and lateral lobes (marked with black arrow).

a)

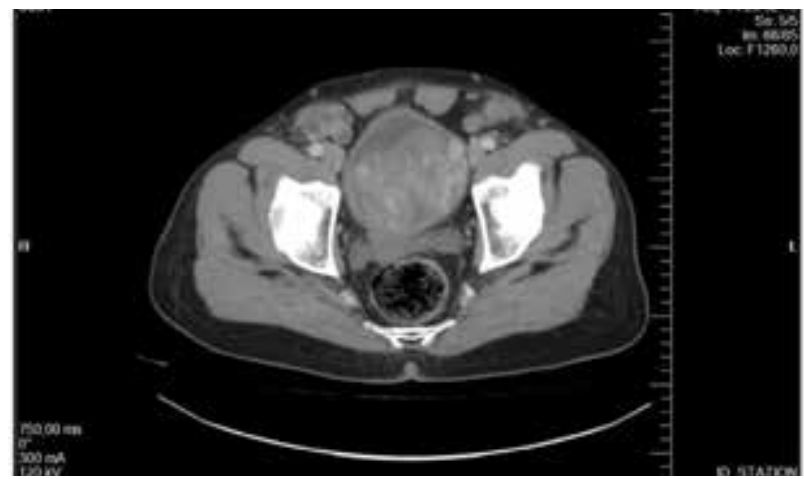

b)

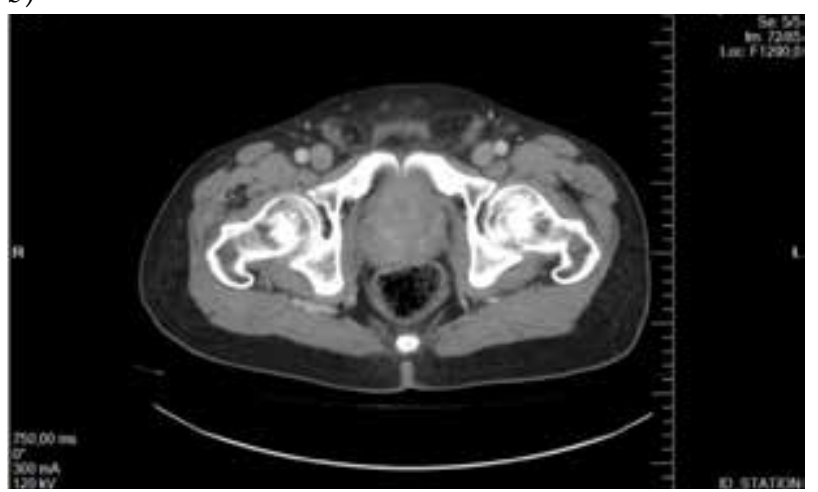

\section{DISCUSSION}

Benign prostatic hyperplasia is a common cause of bladder outlet obstruction and may cause macroscopic hematuria. It is one of the most common diseases in aging men and $60 \%$ of 60 -year-old male patients have $\mathrm{BPH}$ histologically (4).

Prostates weighing more than $500 \mathrm{~g}$ are defined as 'giant prostate hyperplasias' (5). In the literature, more than 20 giant prostatic hyperplasia cases have been reported and giant median lobe is quite rare (6). Although there is no specific definition for giant prostate median lobe hyperplasia in the English literature, Ibrahim AG et al. presented a BPH case called "Giant median lobe enlargement of the prostate mimicking advanced bladder tumour: a case report" in 2014 with 225 g median lobe mimicking a bladder tumor (7). Our case was a BPH case with $180 \mathrm{~g}$ median lobe mimicking a bladder tumor. 
Gross hematuria is not a common symptom for patients presenting for the first time. Macroscopic hematuria is observed in $2.5 \%$ of patients with $\mathrm{BPH}$ according to previous studies (8). Although the etiology of hematuria is not clear in these patients, the increased microvascular density of the prostate or the increased release of vascular endothelial growth factor may be the reasons causing hematuria (9). Because the patient had hematuria and the computed tomography revealed a mass filling the bladder, our provisional diagnosis was a bladder tumor.

Acute or chronic urinary retention, recurrent gross hematuria, urinary tract infection, renal failure, bladder stones and presence of lower urinary tract symptoms resistant to serious medical treatment are indications for surgical treatment. Transurethral prostate resection transurethral prostate incision laser vaporization and enucleation techniques are surgical options for small and mid-sized prostates (4). Although minimally invasive methods have been described, open prostatectomy is still the gold standard procedure for prostates with greater volume (>80 gr) (10). Suprapubic prostatectomy is the enucleation of the prostatic adenoma with an extraperitoneal incision of the lower anterior wall of the bladder. It is preferred especially in cases with a large median lobe (11). In our case, open suprapubic prostatectomy procedure was performed.

Giant median lobe hyperplasia of the prostate is a rare pathology and may mimic bladder tumors by causing painless hematuria. Differential diagnosis is important in shaping the treatment since its symptoms are similar to a bladder tumor.

\section{Declarations}

The authors received no financial support for the research and/or authorship of this article. There is no conflict of interest.

\section{REFERENCES}

1. Joseph CP, Tanagho EA, McAninch JW. Neoplasms of the prostate gland., Smith's General Urology. 15th ed. New York: Lange Medical Books/McGraw-Hill; 2000. 399 p.

2. Fishman JR, Merrill DC. A case of giant prostatic hyperplasia. Urology 1993; 42:336-7

3. Barbaric ZL, Barbaric ZL. Principles of genitourinary radiology. New York. Thieme Medical Publishers 1991; 412-427

4. Thorpe A, Neal D. Benign prostatic hyperplasia. 67th ed. Lancet 2003; 361:1359.

5. Maliakal J, Mousa EE, Menon V. Giant prostatic hyperplasia: fourth largest prostate reported in medical literature. Sultan Qaboos Univ Med J. 2014;14:253-6

6. Üçer O, Baser O, Gümüs B. Giant prostatic hyperplasia: Case report and literature review. Dicle Med J. 2011;38(4):489-91

7. Ibrahim AG, Mohammed BS, Aliyu S, Wabada S, Iya AM, Sanda AB Giant median lobe enlargement of the prostate mimicking advanced bladder tumour: a case report. West Afr J Med. 2014 Jan-Mar;33(1):74-6.

8. Hunter DJ, Berra-Unamuno A, Martin-Gordo A. Prevalence of urinary symptoms and other urological conditions in Spanish men 50 years old or older. J Urol. 1996;155(6):1965-70

9. Foley SJ, Bailey DM. Microvessel density in prostatic hyperplasia. BJU international. 2000;85(1):70-3

10. Rigatti P, Cestari A, Gilling P. The motion: large BPH should be treated by open surgery. Eur Urol. 2007;51(3):845-8.

11. Khan Z, Tahir M, Ashraf HS, Niazi FK, Khan M, Mustafa S, et al. Giant Benign Prostatic Hyperplasia in a Pakistani Patient. Urol Case Rep. 2014; 33-34 